\title{
Neurodevelopmental and psychiatric disorders in females with Turner syndrome: a population-based study
}

\author{
Hanna Björlin Avdic ${ }^{1 *}$ D , Agnieszka Butwicka $2,3,4$, Anna Nordenström, ${ }^{5,6}$, Catarina Almqvist 2,7, \\ Agneta Nordenskjöld ${ }^{5,8}$, Hedvig Engberg ${ }^{5,9+}$ and Louise Frisén ${ }^{1+}$
}

\begin{abstract}
Background: Turner syndrome is the result of the partial or complete absence of an X chromosome in phenotypic girls. This can cause an array of medical and developmental difficulties. The intelligence quotient in females with Turner syndrome has previously been described as uneven, but considered within normal range. Although their social, intellectual, and psychiatric profile is described, it is unclear to what extent these females meet the clinical criteria for neurodevelopmental or psychiatric diagnoses. The aim of this study was to examine the prevalence of neurodevelopmental and psychiatric disorders in females with Turner syndrome.
\end{abstract}

Methods: A retrospective cohort study was performed with a total of 1392 females with Turner syndrome identified through the Swedish National Patient Register and compared with 1:100 age- and sex-matched controls from the general population. The associations between Turner syndrome and diagnoses of neurodevelopmental and/or psychiatric disorders were calculated using conditional logistic regression and is presented as estimated risk (odds ratio, OR, 95\% confidence interval, Cl) in females with Turner syndrome compared with matched controls.

Results: Females with Turner syndrome had a higher risk of neurodevelopmental or psychiatric disorder (OR 1.37, 95\% Cl 1.20-1.57), an eightfold increased risk of intellectual disability (OR 8.59, 95\% Cl 6.58-11.20), and a fourfold increased risk of autism spectrum disorder (OR 4.26, 95\% Cl 2.94-6.18) compared with the controls. In addition, females with Turner syndrome had twice the risk of a diagnosis of schizophrenia and related disorders (OR 1.98, 95\% $\mathrm{Cl} 1.36-2.88)$, eating disorders (OR 2.03,95\% Cl 1.42-2.91), and behavioral and emotional disorders with onset in childhood (OR 2.01, 95\% Cl 1.35-2.99).

Conclusions: Females with Turner syndrome have an increased risk of receiving a diagnosis of neurodevelopmental or psychiatric disorder. This warrants extensive assessment of intellectual and cognitive functions from early age, and increased psychiatric vigilance should be a part of lifelong healthcare for females with Turner syndrome.

Keywords: Turner syndrome, Psychiatric disorder, Neurodevelopmental disorder, ADHD, Autism spectrum disorder, Anxiety, Depression, Eating disorders, Substance misuse, Intellectual disability

\footnotetext{
*Correspondence: hanna.bjorlin.avdic@ki.se

${ }^{\dagger}$ Hedvig Engberg and Louise Frisén contributed equally to this work.

${ }^{1}$ Centre for Psychiatry Research, Department of Clinical Neuroscience, Karolinska Institutet, \& Stockholm Health Care Services, Region

Stockholm, CAP Research Centre, Gävlegatan 22, SE-113 30 Stockholm, Sweden

Full list of author information is available at the end of the article
}

\section{Introduction}

Turner syndrome (TS) is a genetic disorder associated with partial or complete monosomy of the X chromosome resulting in karyotype $45, \mathrm{X}$. TS is one of the most common sex chromosome abnormalities with an incidence ranging from $1 / 2000$ to $1 / 2500$ in live-born females original author(s) and the source, provide a link to the Creative Commons licence, and indicate if changes were made. The images or other third party material in this article are included in the article's Creative Commons licence, unless indicated otherwise in a credit line to the material. If material is not included in the article's Creative Commons licence and your intended use is not permitted by statutory regulation or exceeds the permitted use, you will need to obtain permission directly from the copyright holder. To view a copy of this licence, visit http://creativecommons.org/licenses/by/4.0/. The Creative Commons Public Domain Dedication waiver (http://creativeco mmons.org/publicdomain/zero/1.0/) applies to the data made available in this article, unless otherwise stated in a credit line to the data. 
$[1,2]$. The complete or partial loss of one $\mathrm{X}$ chromosome in girls results in a variation of clinical findings that may include short stature, early loss of ovarian function, cardiac anomalies, hearing loss, visual impairment, and neurocognitive difficulties. The neuroanatomical structure and function of the brain are thought to be highly affected by the characteristics of the $\mathrm{X}$ chromosome. Despite a wide spectrum of variation within the group, the prevailing hypothesis is that the absence or mosaicism of one $\mathrm{X}$ chromosome often presents with a specific pattern of cognitive strengths and deficits [3-6].

Previous studies on relatively small clinical samples reported that most girls and women with TS have a fullscale intelligence quotient (FSIQ) within the normal range but with an uneven intellectual profile with different domains of relative strengths and deficits [7-12]. In addition, females with TS tend to have challenges in specific psychosocial and emotional areas such as behavioral skills, social awareness, and adaptation in social relationships [13-15]. Furthermore, they also have an increased risk of inattention and executive disabilities [16, 17], as well as impairments in face and emotion recognition, and direction of gaze [18-21]. While some studies show an association between TS and autism spectrum disorders (ASD) [22-24], other studies found that the preserved abilities and functions in individuals with TS, while reminiscent of ASD, do not show an increased risk of meeting the criteria for ASD $[25,26]$.

Studies on psychiatric disorders among women with TS are scarce $[27,28]$, but physical stigma, lack of peers, social difficulties, and low self-esteem might contribute to increased levels of depressive and anxiety symptoms, thus placing females with TS at risk of developing psychiatric morbidity $[29,30]$.

Given that previous studies are based on small, highly selected clinical samples often without population references, we carried out a nationwide retrospective cohort study to evaluate the risk of clinical diagnoses of psychiatric and neurodevelopmental disorders in individuals with TS in comparison with matched reference individuals from the general population. The secondary aim was to add to the understanding of the $\mathrm{X}$ chromosome and the etiology of neurodevelopmental and psychiatric disorders by gaining new knowledge of the clinical diagnoses associated with TS.

\section{Methods}

\section{National registers}

All citizens in Sweden have a unique personal identification number that is used in all official records and that enables linkage between population-based registers. For research purposes, Statistics Sweden has generated a key that converts the personal identification number to a unique ID number that results in pseudonymized, de-identified data for each individual. The key is not available to researchers [31]. We performed a matched cohort study using data from the National Patient Register (NPR) and the Total Population Register (TPR) [32]. In 1964, NPR began collecting information on Swedish inpatient care at public hospitals in a few Swedish counties; in 1973, discharge diagnoses for all psychiatric inpatients episodes were added; in 1987, the register included full nationwide coverage of inpatient diagnoses; and since 2001, the register includes all diagnoses from psychiatric outpatient care [33]. The Total Population Register (TPR) records data including birth, death, name change, marital status, family relationships, and migration status updated by the Swedish Tax Agency [32].

\section{Study design and participants}

Females with TS were identified from NPR, both inpatient and outpatient healthcare, using the following diagnostic International Classification of Diseases (ICD) codes [34]: ICD-8 759.50, 310.54, 311.54, 312.54, 314.54, 315.54; ICD-9 758G; and ICD-10 Q96 [33]. Each individual with TS was matched with 100 unaffected female controls by county and date of birth from TPR. The risk of lifetime psychiatric outcomes was stratified depending on what year the individual was diagnosed with TS: (1) individuals diagnosed before 1987, (2) individuals diagnosed from January 1, 1987, through December 31, 2001, and (3) individuals diagnosed from January 1, 2002, through December 31, 2013. This stratification was chosen because it coincides with changes in NPR data collection: the NPR has full nationwide coverage of inpatient diagnoses since 1987 and full coverage of all diagnoses from psychiatric outpatient care since 2002. The study was approved by the Regional Ethical Review Board in Stockholm 2013/862-31.

\section{Outcomes}

Psychiatric disorder was defined as any diagnosis within ICD-8 codes 290-315, ICD-9 codes 290-319, and ICD10 codes F10-F99 in the NPR. The outcome measures were as follows: (1) any NDDs/psychiatric disorders, (2) mental and behavioral disorders due to psychoactive substance use, (3) schizophrenia and related disorders (including schizophrenia schizoaffective disorder), (4) mood disorders (including bipolar, single, and recurrent depressive disorder), (5) suicide attempts, (6) anxiety disorders (including dissociative, stress-related, and somatoform disorders), (7) eating disorders, (8) disorders of adult personality and behavior, (9) mental retardation (intellectual disability (ID)), (10) pervasive developmental disorders (autism spectrum disorders (ASD)), (11) hyperkinetic disorders (attention deficit hyperactivity 
disorder (ADHD)), and (12) behavioral and emotional disorders with onset in childhood. Information of diagnoses of neurodevelopmental and psychiatric disorders was drawn from NPR using the ICD codes. ICD-based definitions are shown in Table 1.

\section{Statistical analyses}

Similar to previous studies [35], we performed a matched cohort study to evaluate the risk of neurodevelopmental and psychiatric disorders in individuals with TS. The condition logistic regression (PROC LOGISTIC with STRATA statement) was used to estimate the odds ratios (OR) with 95\% confidence intervals (CI) for each outcome. Each individual with TS was clustered with her reference individuals matched by the year and county of birth. The statistical analyses were all conducted with the SAS software (version 9.3; Cary, NC, USA).

\section{Results}

We identified 1392 females registered with TS between 1969 and 2013. In 1969, twelve individuals were registered in NPR with a diagnosis of TS. The oldest individual with TS found in NPR was born 1898 and the diagnosis was registered in 1975 .

Analysis of the entire cohort $(n=1392)$ showed that individuals with TS had an eightfold increased risk of intellectual disability diagnosis (OR 8.59, 95\% CI 6.58$11.20)$ and a fourfold increased risk of being diagnosed with ASD (OR 4.26, 95\% CI 2.94-6.18) compared with unaffected controls (Table 2). Individuals with TS also had twice the risk of being diagnosed with schizophrenia and related disorders (OR 1.98, 95\% CI 1.36-2.88), eating disorders (OR 2.03, 95\% CI 1.42-2.91), or behavioral and emotional disorders with onset in childhood (OR 2.01, 95\% CI 1.35-2.99). However, the likelihood of diagnosis of mental and behavioral disorders due to psychoactive substance use (OR 0.64, 95\% CI 0.44-0.92) was lower in females with TS compared to unaffected controls. There was no significant association between TS and ADHD, anxiety disorders, suicide attempts, mood disorders, or disorders of adult personality and behavior (Table 3).

When stratifying the results by the year the individual received her TS diagnosis in the NPR, there was a significantly higher risk of having a diagnosis of psychiatric or neurodevelopmental disorder in the groups diagnosed with TS before 1987, OR 1.59 (1.23-2.04), and after 2002, OR 1.51 (1.21-1.87), compared with controls (Table 3). In contrast, the group diagnosed with TS between 1987 and 2002 showed a non-significant increase compared to controls, OR 1.12 (0.90-1.41).

Sub-analysis for specific diagnoses showed a significantly increased risk of ASD and ID in all three cohorts. Specifically, the cohort diagnosed with TS before 1987 had the highest risk of being diagnosed with ASD or ID compared to the controls. In addition, the cohort with a diagnosis of TS before 1987 was the only group that had a significantly increased risk of schizophrenia and related disorders and ADHD. The cohort diagnosed with TS between 1987 and 2001 showed a significantly increased risk of eating disorders compared to the other cohorts, as

Table 1 ICD codes used to define neurodevelopmental and psychiatric disorders [34]

\begin{tabular}{|c|c|c|c|}
\hline Diagnoses & ICD-10 codes, > 2001 & Equivalent ICD-9 codes, 1987-2001 & Equivalent ICD-8 codes, $<1987$ \\
\hline $\begin{array}{l}\text { Any neurodevelopmental disorders/psychiatric } \\
\text { disorders }\end{array}$ & F10-F99 & $290-319$ & $290-315$ \\
\hline $\begin{array}{l}\text { Mental and behavioral disorders due to psychoactive } \\
\text { substance use }\end{array}$ & F10-F19 & $291,303,304$ & $291,303,304,305 A, 305 X$ \\
\hline $\begin{array}{l}\text { Schizophrenia and related disorders (including } \\
\text { schizophrenia schizoaffective disorder) }\end{array}$ & F20-29 & $295,297,298$ & $295,297-299$ \\
\hline $\begin{array}{l}\text { Mood disorders (including bipolar, single, and recur- } \\
\text { rent depressive disorder) }\end{array}$ & F30-39 & 296, 300E, 311 & $296,300.40$ \\
\hline Suicide attempts & X60-X84 & E950-E959 & E950-E959 \\
\hline $\begin{array}{l}\text { Anxiety disorders (including dissociative, stress-related } \\
\text { and somatoform disorders) }\end{array}$ & $\mathrm{F} 40-48$ & 300, 300A-300D, 300F-300X, 308-309 & $300.00-300.30,300.50-300.99,307$ \\
\hline Eating disorders & F50 & $307 \mathrm{~B}, 307 \mathrm{~F}$ & - \\
\hline Disorders of adult personality and behavior & F60-F62, F69 & 301 & 301 \\
\hline Mental retardation (ID) & F70-F79 & $317-319$ & $310-315$ \\
\hline Pervasive developmental disorders (ASD) & F84 & $299 A$ & - \\
\hline Hyperkinetic disorders (ADHD) & F90 & 314 & - \\
\hline $\begin{array}{l}\text { Behavioral and emotional disorders with onset in } \\
\text { childhood }\end{array}$ & F91-98 & $312-313$ & - \\
\hline
\end{tabular}

$I D$ intellectual disability, $A S D$ autism spectrum disorder, $A D H D$ attention deficit hyperactivity disorder 
Table 2 Neurodevelopmental/psychiatric disorders in girls and women with Turner syndrome compared with age-matched controls (1:100 controls)

\begin{tabular}{|c|c|c|c|c|}
\hline Diagnoses & $\begin{array}{l}\text { Turner } \\
\text { syndrome } \\
N(\%)\end{array}$ & Matched controls $N(\%)$ & OR $(95 \% \mathrm{Cl})$ & $P$ \\
\hline Any neurodevelopmental disorders/psychiatric disorders & $283(20.33)$ & $21948(15.77)$ & $1.37(1.20-1.57)$ & $<.0001$ \\
\hline Mental and behavioral disorders due to psychoactive substance use & $30(2.16)$ & 4635 (3.33) & $0.64(0.44-0.92)$ & 0.0091 \\
\hline $\begin{array}{l}\text { Schizophrenia and related disorders (including schizophrenia schizoaffective disor- } \\
\text { der) }\end{array}$ & $29(2.08)$ & $1493(1.07)$ & $1.98(1.36-2.88)$ & 0.0012 \\
\hline Mood disorders (including bipolar, single, and recurrent depressive disorder) & $79(5.68)$ & $8606(6.18)$ & $0.91(0.72-1.15)$ & 0.4252 \\
\hline Suicide attempt & $19(1.36)$ & $2158(1.55)$ & $0.88(0.56-1.39)$ & 0.5682 \\
\hline Anxiety disorders (including dissociative, stress-related, and somatoform disorders) & $96(6.90)$ & $11210(8.05)$ & $0.84(0.68-1.04)$ & 0.1034 \\
\hline Eating disorders & $32(2.30)$ & $1609(1.16)$ & $2.03(1.42-2.91)$ & 0.0004 \\
\hline Disorders of adult personality and behavior & $17(1.22)$ & $1720(1.24)$ & $0.99(0.61-1.60)$ & 0.9613 \\
\hline Mental retardation (ID) & $62(4.45)$ & $760(0.55)$ & $8.59(6.58-11.20)$ & $<.0001$ \\
\hline Pervasive developmental disorders (ASD) & $30(2.16)$ & $726(0.52)$ & $4.26(2.94-6.18)$ & $<.0001$ \\
\hline Hyperkinetic disorders (ADHD) & $22(1.58)$ & $1732(1.24)$ & $1.28(0.83-1.96)$ & 0.2771 \\
\hline Behavioral and emotional disorders with onset in childhood & $26(1.87)$ & $1319(0.95)$ & $2.01(1.35-2.99)$ & 0.0017 \\
\hline
\end{tabular}

OR odds ratio, ID intellectual disability, $A S D$ autism spectrum disorder, $A D H D$ attention deficit hyperactivity disorder

well as significant decreased risk of mood, anxiety, and mental and behavioral disorders due to psychoactive substance use. The cohort diagnosed with TS after 2002 was the only group that showed increased risk of behavioral and emotional disorders with onset in childhood, such as conduct or emotional disorders.

\section{Discussion}

In this population-based study of Turner syndrome, we compared the risk of neurodevelopmental and psychiatric diagnoses in girls and women diagnosed with TS with matched reference individuals from the general population. Our study identifies a significantly increased risk of ID and other clinical diagnoses, such as schizophrenia and related disorders, and eating, behavioral, and emotional disorders with onset in childhood. The findings also confirm previous studies that have shown a high risk of ASD in females with TS [22-24]. This is also the first study to report on mental and behavioral disorders due to psychoactive substance use in individuals with TS, showing that girls and women with TS have a lower risk of diagnosis with mental and behavioral disorders due to psychoactive substance use compared to the general population.

The most important finding was more than eightfold increased risk of ID. The intellectual level in TS is described as slightly lower than average but within normal range [6-8]. However, with small numbers $(n=50)$ of TS individuals, previous studies have been largely underpowered to detect any difference in fulfilling the diagnostic criteria for ID [6, 8]. A higher incidence of ASD has previously been shown by Creswell and Skuse
[22]. However, this is the first study to estimate risk in comparison with unaffected population controls. A contributing factor in identifying the high risk of ID and ASD in females with TS in Sweden is probably the almost complete coverage of the national patient registers, including individuals with severe intellectual disabilities or restrictive autistic behaviors that might hinder study participation. However, the increased incidence of ID and ASD might also reflect the fact that individuals presenting with major intellectual disabilities or restrictive autistic behaviors are more likely to be genetically investigated, and thus diagnosed with TS.

The increased risk of ASD in this study is consistent with previous findings that approximately $3 \%$ of individuals with TS fulfill the ICD-10 diagnostic criteria for autism [22], twice the estimated incidence in the general population (1.5\%) [36]. These results reflect previously well-described social difficulties in individuals with TS, who in comparison with girls and women in the same age group seem to have fewer friends and engage in fewer social activities [14]. Increased interest in the social deficits in TS might implicate an increased awareness of ASD or autistic traits associated with TS. Nevertheless, large studies that present prevalence, based on diagnostic criteria, are lacking.

Stratifying the results in relation to time of diagnosis provides an interesting opportunity to spot possible differences between the time periods. However, the relatively small sample sizes lead to fewer opportunities to draw reliable conclusions. Individuals with TS who were diagnosed before 1987 (23.6\%) had an increased risk of receiving a diagnosis of ASD or ID compared to 


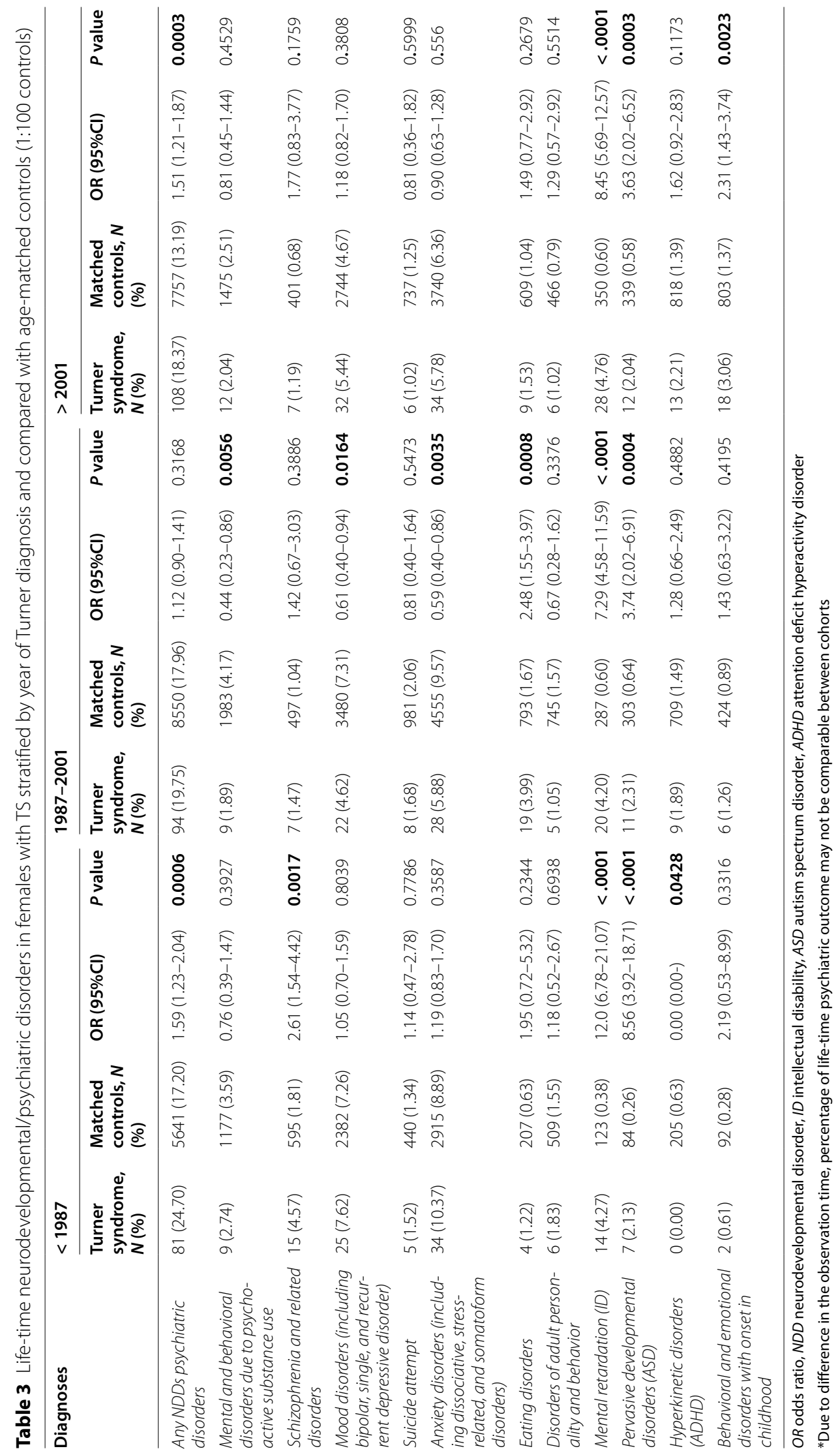


the groups diagnosed in 1987-2002, or after 2002. This might, again, reflect that the patient register only covered discharge diagnoses before 1987, thus including only the women with the most pronounced phenotypes and disabilities in need of inpatient care. In addition, the diagnosis and traits of autism have gained more attention during the last decade, with changes in the reporting practices and diagnostic criteria, which also might reflect an increase in the number of individuals diagnosed with ASD in general [37, 38].

Previous studies have shown a clear association between TS and executive dysfunctions in TS described by the diagnostic criteria for ADHD [10, 39], but surprisingly few individuals in this study had been diagnosed with ADHD. Thus, women with TS may very well be under-diagnosed with ADHD, as these dysfunctions may have been attributed to the diagnosis of TS and not assessed as a separate dysfunction. Our results may primarily reflect a previous lack of knowledge about ADHD; however, it is important to stress the correct assessment of symptoms regardless of a present syndrome.

Literature is scarce regarding the risk of schizophrenia and related disorders, but one previous study found schizophrenia to have an incidence of $1 \%$ in a group of 325 individuals with TS [28]. However, women with a diagnosis of schizophrenia showed a threefold increase for a diagnosis of TS [40, 41]. Interestingly, the mosaic karyotype 45,X/46,XX was clearly overrepresented in women with schizophrenia compared to other karyotypes of TS [40, 41]. In comparison, in this study, the prevalence was $2.08 \%$ and the odds ratio 1.98 (95\% CI 1.36-2.88), but included all schizophrenia and related disorders, not just schizophrenia. Solely evaluation of the diagnosis of schizophrenia alone can give misleading results, as the diagnosis of schizophrenia is not often confirmed in the first episode of psychosis, especially in adolescents [42].

Furthermore, our results show that girls and women with TS have twice the risk of receiving an eating-disorder diagnosis compared with unaffected controls (OR 2.03, 95\% CI 1.42-2.91). There are few studies on TS and eating disorders, but in one study of 100 females with TS, 46 of them had previous psychiatric diagnoses, which of six individuals (13\%) had been diagnosed with an eating disorders (five with anorexia and one with bulimia) [27]. In a European cross-sectional study of the self-reported data of 325 individuals with TS, $10.8 \%$ reported eating disorder as a previous or current psychiatric diagnosis [28]. When stratifying our results, women with a diagnosis of TS registered between 1987 and 2001 had a significantly higher risk of being diagnosed with eating disorders, which is consistent with the overall prevalence of anorexia nervosa among Swedish female twins, 1.20\%
[43]. This might be explained by increases in the rates of bulimia in the general population during the 1980s and early 1990s; since then, rates have remained constant or decreased slightly [44]. The higher risk of eating disorder in TS may also be a result of ascertainable bias, since women with TS have regular medical examinations and are thus diagnosed to a greater extent.

The risk of anxiety or mood disorders in individuals with TS in this study was not significantly greater than in the general population. In contrast, a previous study found that $52 \%$ of a sample of 100 females with TS met criteria for current or past depressive or anxiety disorders during their lifetime [27]. This can suggest that mood and anxiety disorders in TS remain largely undiagnosed, but a probable causal factor may also be that the data source in the current study, the NPR, does not include diagnoses from the primary care facilities where mild forms of anxiety and depression are treated. In our results, the frequency of mood- and anxiety-related diagnoses were lower overall in females with TS compared to controls, with the lowest numbers among women whose TS diagnosis was registered 1987-2001. However, this may also reflect a tendency to describe psychiatric symptoms and conditions in individuals with TS as sub-phenomena of the syndrome, rather than separate diagnoses.

The cohort of individuals diagnosed with TS after 2002 was the only cohort with a significant increase in risk of behavioral and emotional disorders with onset in childhood. Individuals in this cohort can be assumed to be younger compared to the other cohorts, as methods for recognizing and detecting genetic syndrome are likely to be more effective over time, increasing the likelihood of obtaining a diagnosis at a younger age. Since an ICD equivalent to the diagnostic group "behavioral and emotional disorders with onset in childhood" did not exist until 1987, and includes diagnoses preferably made in childhood, this excludes a large part of the study population who were children before 1987. Thus, it is not surprising that the group diagnosed 2002-2013 has a significantly higher risk, but no definite conclusions can be drawn from this difference, since cohorts are stratified by year of registered TS diagnosis, rather than year of birth.

Correct investigation and diagnosis are essential in order to access proper care [30] as well as make adjustments in school or at work, training interventions, and drug treatment [7, 45-47]. Early detection of sex chromosomal abnormalities and intervention has, in general, been shown to have a positive impact on psychosocial, cognitive, and reproductive ability [30].

Our results support previous molecular findings suggesting an effect of X-linked genetic information in the etiology of neurodevelopmental disorders $[48,49]$. Further describing the phenotype in TS may also provide 
better understanding of sexual dimorphism, as well as clues to a deeper understanding of X-linked neurodevelopmental disorders $[48,50]$.

\section{Strengths and limitations}

The strength of this study is the population-based design data from national registries with nationwide coverage. However, there are limitations related to register-based methodology. For example, the exact karyotype, whether it is mosaicism or not, cannot be distinguished by ICD codes in the registers. We stratified the results to examine whether they differed between the groups due to the tendency to identify different diagnoses of neurodevelopmental disorders and psychiatric disorders over time. However, no reliable results could be found, as the groups became too small and the coverage in the registers varied too much. In addition, all data is decoded, so we cannot link individuals with their medical history and can therefore not know at what exact age the individuals received their diagnosis, only when it was added to the register. Aspects of medical treatment cannot be assessed in this study since the Prescribed Drug Register has only been in place since 2005 [51], and thus would not mirror treatment in our cohort. Furthermore, girls and women with TS are under regular care and make frequent visits to health care, receiving more intense surveillance for psychiatric outcomes than the general population, thus increasing the possibility of ascertainment bias and Berkson's bias. Health care is publicly funded with universal access to both primary care and non-primary care in Sweden [52]. However, primary care is not included by NPR and is thus not included in our data. The absence of data from primary care may explain an unexpectedly low risk of anxiety and depressive disorders since milder forms of anxiety and depression are treated in primary care. On the other hand, this reinforces indications that ADHD might be under-diagnosed in individuals with TS since ADHD is treated in non-primary care. Most diagnoses in NPR have a positive predictive value (PPV) of 85-95\%, but the figures vary according to diagnosis [33]. Among psychiatric diagnoses, PPV have ranged from 86 to $95 \%$ for schizophrenia and related disorders [53, 54], and $96 \%$ for ASD [55]. However, the results only reflect diagnoses, and as always in registry studies, the diagnosis cannot be verified by going back to the patient's chart.

\section{Conclusion}

This study not only confirms prior findings regarding the phenotype of TS but also adds new knowledge by presenting higher prevalence of ID and ASD than previously reported. These findings indicate that assessments related to development, intellectual functions, and psychiatric symptoms are warranted from an early age in females with TS in order to offer proper treatment, training interventions, and adjustments in their everyday life.

\begin{abstract}
Abbreviations
ICD: International Classification of Diseases; NPR: National Patient Register; TPR: Total Population Register; CDR: Cause of Death Register; NND: Neurodevelopmental disorders; ADHD: Attention-deficit hyperactivity disorder; ASD: Autism spectrum disorders.
\end{abstract}

\section{Acknowledgements}

Not applicable.

\begin{abstract}
Authors' contributions
$\mathrm{ANo}, \mathrm{ANd}, \mathrm{CA}$, and LF developed the idea and topic of the manuscript and drafted the method. $A B$ did the statistical analyses. $H A B, A B$, and $H E$ each wrote and edited the manuscript. All authors contributed to the ideas expressed in the manuscript. All authors read and approved the final manuscript.
\end{abstract}

Funding

Supported by grants provided by the Stockholm County Council (no. 20160295) and the Swedish Research Council (no. 2017-02740). Open access funding provided by Karolinska Institute.

\section{Availability of data and materials}

The datasets used and/or analyzed during the current study are available from the corresponding author on reasonable request.

\section{Declarations}

Ethics approval and consent to participate

This study was approved by the Regional Ethical Review Board in Stockholm 2013/862-31.

\section{Consent for publication}

Not applicable.

\section{Competing interests}

The authors declare that they have no competing interests.

\section{Author details}

${ }^{1}$ Centre for Psychiatry Research, Department of Clinical Neuroscience, Karolinska Institutet, \& Stockholm Health Care Services, Region Stockholm, CAP Research Centre, Gävlegatan 22, SE-113 30 Stockholm, Sweden. Department of Medical Epidemiology and Biostatistics, Karolinska Institutet, Stockholm, Sweden. ${ }^{3}$ Department of Child Psychiatry, Medical University of Warsaw, Warsaw, Poland. ${ }^{4}$ Child and Adolescent Psychiatry, Stockholm Health Care Services, Stockholm County Council, Stockholm, Sweden. ${ }^{5}$ Department of Women's and Children's Health, Karolinska Institutet, Stockholm, Sweden. ${ }^{6}$ Department of Pediatric Endocrinology, Astrid Lindgren Children's Hospital, Karolinska University Hospital, Stockholm, Sweden. ${ }^{7}$ Pediatric Allergy and Pulmonology Unit, Astrid Lindgren Children's Hospital, Stockholm, Sweden.

${ }^{8}$ Pediatric Surgery, Astrid Lindgren Children's Hospital, Karolinska University Hospital, Stockholm, Sweden. ${ }^{9}$ Department of Gynecology and Reproductive Medicine, Karolinska University Hospital, Stockholm, Sweden.

Received: 7 October 2020 Accepted: 14 October 2021

Published online: 27 October 2021

\section{References}

1. Nielsen J, Wohlert M. Chromosome abnormalities found among 34,910 newborn children: results from a 13-year incidence study in Arhus, Denmark. Hum Genet. 1991:87(1):81-3.

2. Gravholt $\mathrm{CH}$, Juul S, Naeraa RW, Hansen J. Prenatal and postnatal prevalence of Turner's syndrome: a registry study. BMJ. 1996;312(7022):16-21. https://doi.org/10.1136/bmj.312.7022.16. 
3. Marco EJ, Skuse DH. Autism-lessons from the X chromosome. Soc Cogn Affect Neurosci. 2006;1(3):183-93.

4. Knickmeyer RC, Hooper SR. The deep biology of cognition: moving toward a comprehensive neurodevelopmental model of Turner syndrome. Am J Med Genet. 2019;181(1):91-9.

5. Gravholt CH, Andersen NH, Conway GS, Dekkers OM, Geffner ME, Klein $\mathrm{KO}$, et al. Clinical practice guidelines for the care of girls and women with Turner syndrome: proceedings from the 2016 Cincinnati International Turner Syndrome Meeting. Eur J Endocrinol. 2017;177(3):G1-G70.

6. Hong DS, Hoeft F, Marzelli MJ, Lepage JF, Roeltgen D, Ross J, et al. Influence of the X-chromosome on neuroanatomy: evidence from Turner and Klinefelter syndromes. J Neurosci. 2014;34(10):3509-16.

7. Mazzocco MMM. The cognitive phenotype of Turner syndrome: specific learning disabilities. Int Congress Ser. 2006;1298:83-92.

8. Temple CM, Carney RA. Intellectual functioning of children with Turner syndrome: a comparison of behavioural phenotypes. Dev Med Child Neurol. 1993;35(8):691-8.

9. Ross J, Zinn A, McCauley E. Neurodevelopmental and psychosocial aspects of Turner syndrome. Ment Retard Dev Disabil Res Rev. 2000:6(2):135-41.

10. Russell HF, Wallis D, Mazzocco MM, Moshang T, Zackai E, Zinn AR, et al. Increased prevalence of ADHD in Turner syndrome with no evidence of imprinting effects. J Pediatr Psychol. 2006;31(9):945-55.

11. Baker JM, Klabunde M, Jo B, Green T, Reiss AL. On the relationship between mathematics and visuospatial processing in Turner syndrome. J Psychiatr Res. 2020;121:135-42.

12. Hong D, Scaletta Kent J, Kesler S. Cognitive profile of Turner syndrome. Dev Disabil Res Rev. 2009;15(4):270-8.

13. Lepage JF, Dunkin B, Hong DS, Reiss AL. Impact of cognitive profile on social functioning in prepubescent females with Turner syndrome. Child Neuropsychol. 2013:19(2):161-72.

14. McCauley E, Feuillan P, Kushner H, Ross JL. Psychosocial development in adolescents with Turner syndrome. J Dev Behav Pediatr. 2001;22(6):360-5.

15. Wolstencroft J, Skuse D. Social skills and relationships in Turner syndrome. Curr Opin Psychiatry. 2019;32(2):85-91.

16. Mauger C, Lancelot C, Roy A, Coutant R, Cantisano N, Le Gall D. Executive functions in children and adolescents with Turner syndrome: a systematic review and meta-analysis. Neuropsychol Rev. 2018;28(2):188-215.

17. Green T, Bade Shrestha S, Chromik LC, Rutledge K, Pennington BF, Hong DS, et al. Elucidating $X$ chromosome influences on attention deficit hyperactivity disorder and executive function. J Psychiatr Res. 2015;68:217-25.

18. Lawrence K, Kuntsi J, Coleman M, Campbell R, Skuse D. Face and emotion recognition deficits in Turner syndrome: a possible role for $\mathrm{X}$-linked genes in amygdala development. Neuropsychology. 2003;17(1):39-49.

19. Lawrence K, Campbell R, Swettenham J, Terstegge J, Akers R, Coleman M, et al. Interpreting gaze in Turner syndrome: impaired sensitivity to intention and emotion, but preservation of social cueing. Neuropsychologia. 2003:41(8):894-905.

20. Mazzola F, Seigal A, MacAskill A, Corden B, Lawrence K, Skuse DH. Eye tracking and fear recognition deficits in Turner syndrome. Soc Neurosci. 2006; 1 (3-4):259-69.

21. Elgar K, Campbell R, Skuse D. Are you looking at me? Accuracy in processing line-of-sight in Turner syndrome. Proceedings. 2002:269(1508):2415-22.

22. Creswell CS, Skuse DH. Autism in association with Turner syndrome: genetic implications for male vulnerability to pervasive developmental disorders. Neurocase. 1999;5(6):511-8.

23. Wolstencroft JMW, Skuse D. Turner syndrome: mental health and social skills from childhood to emerging adulthood. In: 21st European Congress of Endocrinology. Lyon: Endocrine Abstracts Endocrine Abstracts 2019; 2019

24. Wolstencroft J, Srinivasan R, Mandy W, Imagine ID, Skuse D. Turner syndrome: mental health and social skills from childhood to adolescense. J Intellect Disabil Res. 2017;61(9):827.

25. Lepage JF, Lortie M, Deal CL, Théoret H. Empathy, autistic traits, and motor resonance in adults with Turner syndrome. Soc Neurosci. 2014;9(6):601-9.

26. Hong DS, Dunkin B, Reiss AL. Psychosocial functioning and social cognitive processing in girls with Turner syndrome. J Dev Behav Pediatr. 2011;32(7):512-20.
27. Cardoso G, Daly RJ, Haq NA, Hanton L, Rubinow DR, Bondy CA, et al. Current and lifetime psychiatric illness in women with Turner syndrome. Gynecol Endocrinol. 2004;19(6):313-9.

28. de Vries ALC, Roehle R, Marshall L, Frisén L, van de Grift TC, Kreukels BPC, et al. Mental health of a large group of adults with disorders of sex development in six European countries. Psychosom Med. 2019;81(7):629-40.

29. Kiliç BG, Ergür AT, Ocal G. Depression, levels of anxiety and selfconcept in girls with Turner's syndrome. J Pediatr Endocrinol Metab. 2005:18(11):1111-7.

30. Hong DS, Reiss AL. Cognitive and neurological aspects of sex chromosome aneuploidies. Lancet Neurol. 2014;13(3):306-18.

31. Van Der Wel KA, Östergren O, Lundberg O, Korhonen K, Martikainen $P$, Andersen A-MN, et al. A gold mine, but still no Klondike: Nordic register data in health inequalities research. Scand J Public Health. 2019;47(6):618-30.

32. Ludvigsson JF, Almqvist C, Bonamy A-KE, Ljung R, Michaëlsson K, Neovius $M$, et al. Registers of the Swedish total population and their use in medical research. Eur J Epidemiol. 2016;31(2):125-36.

33. Ludvigsson JF, Andersson E, Ekbom A, Feychting M, Kim JL, Reuterwall $C$, et al. External review and validation of the Swedish national inpatient register. BMC Public Health. 2011;11:450.

34. World Health Organization. ICD-10: international statistical classification of diseases and related health problems: tenth revision, 2nd ed. World Health Organization; 2004.

35. Ohlsson Gotby V, Söder O, Frisén L, Serlachius E, Bölte S, Almqvist C, et al. Hypogonadotrophic hypogonadism, delayed puberty and risk for neurodevelopmental disorders. J Neuroendocrinol. 2019:31(11):e12803.

36. Lyall K, Croen L, Daniels J, Fallin MD, Ladd-Acosta C, Lee BK, et al. The changing epidemiology of autism spectrum disorders. Annu Rev Public Health. 2017;38:81-102.

37. Hansen SN, Schendel DE, Parner ET. Explaining the increase in the prevalence of autism spectrum disorders: the proportion attributable to changes in reporting practices. JAMA Pediatr. 2015;169(1):56-62.

38. Chiarotti F, Venerosi A. Epidemiology of autism spectrum disorders: a review of worldwide prevalence estimates since 2014. Brain Sci. 2020;10(5):274

39. Saad K, Abdelrahman AA, Abdel-Raheem YF, Othman ER, Badry R, Othman HA, et al. Turner syndrome: review of clinical, neuropsychiatric, and EEG status: an experience of tertiary center. Acta Neurol Belg. 2014;114(1):1-9.

40. Prior TI, Chue PS, Tibbo P. Investigation of Turner syndrome in schizophrenia. Am J Med Genet. 2000:96(3):373-8.

41. Roser P, Kawohl W. Turner syndrome and schizophrenia: a further hint for the role of the $\mathrm{X}$-chromosome in the pathogenesis of schizophrenic disorders. World J Biol Psychiatry. 2010;11(2 Pt 2):239-42.

42. Häfner H, Maurer K, Löffler W, Riecher-Rössler A. The influence of age and sex on the onset and early course of schizophrenia. Br J Psychiatry. 1993;162:80-6.

43. Bulik CM, Sullivan PF, Tozzi F, Furberg H, Lichtenstein P, Pedersen NL. Prevalence, heritability, and prospective risk factors for anorexia nervosa. Arch Gen Psychiatry. 2006;63(3):305-12.

44. Smink FRE, van Hoeken D, Hoek HW. Epidemiology of eating disorders: incidence, prevalence and mortality rates. Curr Psychiatry Rep. 2012;14(4):406-14.

45. Hutaff-Lee C, Bennett E, Howell S, Tartaglia N. Clinical developmental, neuropsychological, and social-emotional features of Turner syndrome. Am J Med Genet C Semin Med Genet. 2019;181(1):126-34.

46. Fernell E, Wilson P, Hadjikhani N, Bourgeron T, Neville B, Taylor D, et al. Screening, intervention and outcome in autism and other developmental disorders: the role of randomized controlled trials. J Autism Dev Disord. 2014;44(8):2074-6.

47. Wolstencroft J, Mandy W, Skuse D. Experiences of social interaction in young women with Turner syndrome: a qualitative study. Child Care Health Dev. 2020:46(1):46-55.

48. Tzschach A, Grasshoff U, Beck-Woedl S, Dufke C, Bauer C, Kehrer M, et al. Next-generation sequencing in X-linked intellectual disability. Eur J Hum Genet. 2015;23(11):1513-8.

49. Yanagi K, Kaname T, Wakui K, Hashimoto O, Fukushima Y, Naritomi K. Identification of four novel synonymous substitutions in the X-linked genes neuroligin 3 and neuroligin $4 X$ in Japanese patients with autistic spectrum disorder. Autism Res Treat. 2012;2012:724072. 
50. Green T, Flash S, Reiss AL. Sex differences in psychiatric disorders: what we can learn from sex chromosome aneuploidies. Neuropsychopharmacology. 2019;44(1):9-21.

51. Wettermark B, Hammar N, Fored CM, Leimanis A, Otterblad Olausson P, Bergman U, et al. The new Swedish Prescribed Drug Register--opportunities for pharmacoepidemiological research and experience from the first six months. Pharmacoepidemiol Drug Saf. 2007;16(7):726-35.

52. Wettergren B, Blennow M, Hjern A, Soder O, Ludvigsson JF. Child health systems in Sweden. J Pediatr. 2016;177S:S187-202.

53. Dalman C, Broms J, Cullberg J, Allebeck P. Young cases of schizophrenia identified in a national inpatient register--are the diagnoses valid? Soc Psychiatry Psychiatr Epidemiol. 2002;37(11):527-31.
54. Lichtenstein P, Bjork C, Hultman CM, Scolnick E, Sklar P, Sullivan PF. Recurrence risks for schizophrenia in a Swedish national cohort. Psychol Med. 2006;36(10):1417-25

55. Idring S, Rai D, Dal H, Dalman C, Sturm H, Zander E, et al. Autism spectrum disorders in the Stockholm Youth Cohort: design, prevalence and validity. PLoS One. 2012;7(7):e41280.

\section{Publisher's Note}

Springer Nature remains neutral with regard to jurisdictional claims in published maps and institutional affiliations.
Ready to submit your research? Choose BMC and benefit from:

- fast, convenient online submission

- thorough peer review by experienced researchers in your field

- rapid publication on acceptance

- support for research data, including large and complex data types

- gold Open Access which fosters wider collaboration and increased citations

- maximum visibility for your research: over $100 \mathrm{M}$ website views per year

At BMC, research is always in progress.

Learn more biomedcentral.com/submissions 